\title{
Subcutaneous Panniculitis-like T-Cell Lymphoma Without Erythema and Subcutaneous Tumors
}

\author{
Keiko Wakumoto,* Kazunari Sugita $\uparrow$ and Osamu Yamamoto $\dagger$ \\ *Division of Dermatology, Matsue Red Cross Hospital, Matsue 690-0886, Japan and †Division of Dermatology, Department of \\ Medicine of Sensory and Motor Organs, School of Medicine, Faculty of Medicine, Tottori University, Yonago 683-8503, Japan
}

\begin{abstract}
We report a case of subcutaneous panniculitis-like T-cell lymphoma with diffuse indurated lesions without erythema. A 27-year-old man was referred to us with a 1-month history of fever, general fatigue and indurated skin lesions. The initial examination revealed indurated skin lesions without erythema and subcutaneous tumors in the right lower abdomen, back and buttocks. Histopathology showed a panniculitis predominantly in lobular pattern, and infiltration of atypical lymphocytes in the subcutaneous tissue. Characteristically, there was rimming of individual fat cells by surrounding atypical lymphocytes. Results of laboratory examinations showed hemophagocytic syndrome (HPS). Based on these findings, we made a diagnosis of subcutaneous panniculitis-like T-cell lymphoma without erythema and subcutaneous tumors with HPS. To our knowledge, there has been no report of SPTCL with diffuse indurated lesions without erythema, tumors, or plaque, all of which are considered to be typical characteristics of SPTCL. Positron emission tomography / computed tomography (PET/CT) showed noticeable thickening of diffuse subcutaneous involvement throughout the body. Hence, PET/CT is a useful for the detection of SPTCL as well as its distribution.
\end{abstract}

Key words hemophagocytic syndrome; subcutaneous panniculitis-like T-cell lymphoma

Subcutaneous panniculitis-like T-cell lymphoma (SPTCL) is defined as a cytotoxic T-cell lymphoma characterized by the presence of primarily subcutaneous infiltrates of pleomorphic $\mathrm{T}$ cells and numerous macrophages. SPTCL predominantly affects the legs and can be sometime complicated by hemophagocytic syndrome (HPS). ${ }^{1}$ Here, we report the first case of SPTCL on the trunk with an unusal clinical manifestation.

Corresponding author: Keiko Wakumoto, MD, PhD

w_hikaru0622@yahoo.co.jp

Received 2020 April 15

Accepted 2020 November 24

Online published 2020 December 25

Abbreviations: HPS; hemophagocytic syndrome, PET/CT, Positron emission tomography / computed tomography; SPTCL, Subcutaneous panniculitis-like T-cell lymphoma

\section{PATIENT REPORT}

A 27-year-old man was referred to us with a 1-month history of high fever, general fatigue and indurated skin lesions. The initial clinical examination revealed a diffuse skin induration from the right lower abdomen, to the back and buttocks without erythema (Fig. 1a). Laboratory studies revealed pancytopenia with a white blood cell count of $1.7 \times 10^{3} / \mu \mathrm{L}$ (normal, 4.0 to $9.4 \times$ $10^{3} / \mu \mathrm{L}$ ) with atypical lymphocytes, hemoglobin level 8.9 $\mathrm{g} / \mathrm{dL}$ (normal, 13.5 to $17.5 \mathrm{~g} / \mathrm{dL}$ ) and platelet count of 52 $\times 10^{3} / \mu \mathrm{L}$ (normal, 150 to $370 \times 10^{3} \mu \mathrm{L}$ ). Blood chemistry tests showed elevated levels of alanine transaminase (ALT) (266 U/L, normal: 11-34 U/L), aspartate transaminase (AST) (67 U/L, normal, 7-34 U/L), and lactate dehydrogenase (LDH) (3051 U/L, normal, 110-230 U/L). Serum level of ferritin was $31610 \mathrm{ng} / \mathrm{mL}$ (normal, 150$220 \mathrm{ng} / \mathrm{mL}$ ). Serum soluble interleukin (IL) 2 receptor was significantly elevated $(6676 \mathrm{U} / \mathrm{mL}$, normal, 127-582 $\mathrm{U} / \mathrm{mL}$ ). Histopathology showed a predominantly lobular panniculitis, and infiltration of medium and large irregularly-shaped lymphocytes into the subcutaneous tissue (Fig. 1b). Large histiocytes engulfing red blood cells were identified in the subcutaneous tissue. The epidermis and dermis are mostly uninvolved.

Immunohistochemically, the atypical lymphocytes were positive for CD3, CD8 and granzyme B (Figs. $1 \mathrm{c}$ and d). Atypical $\mathrm{CD} 8^{+} \mathrm{T}$ cells showed rimming of individual fat cells. Southern blot analysis revealed a monoclonal rearrangement of the T-cell receptor (TCR)- $\beta$ chain gene. Epstein-Barr virus was not detected by in situ hybridization. Based on clinical and histopathological findings, the patient was diagnosed as having SPTCL associated with HPS. Positron emission tomography / computed tomography (PET/CT) showed noticeable ill-defined thickening of the tissue from the right lower abdomen to the back and buttocks and throughout the body (Fig. 1e). The patient was treated with intravenous administration of methylprednisolone pulse therapy. Systemic symptoms and laboratory abnormalities gradually improved in response to the therapy. 

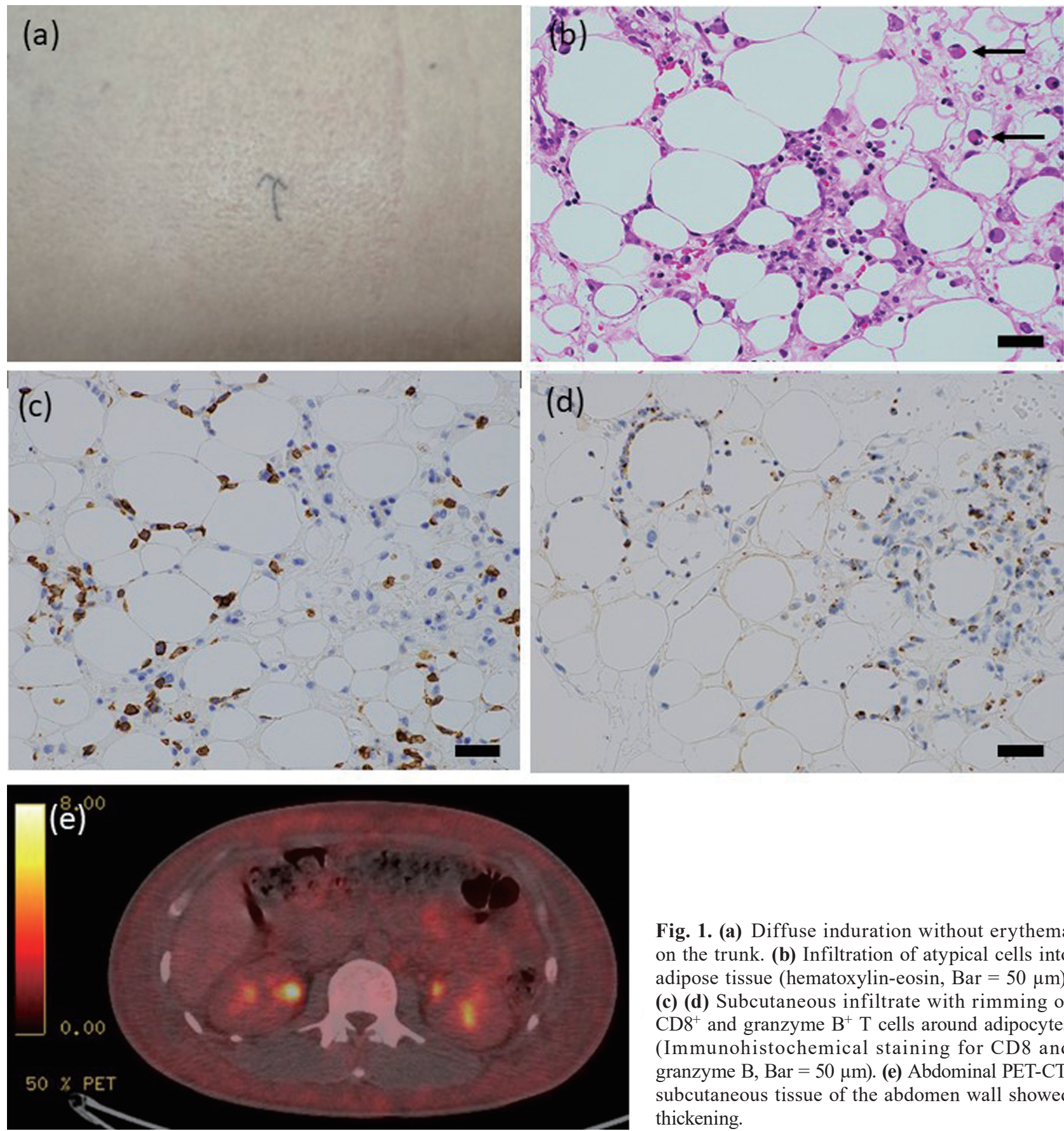

Fig. 1. (a) Diffuse induration without erythema on the trunk. (b) Infiltration of atypical cells into adipose tissue (hematoxylin-eosin, Bar $=50 \mu \mathrm{m}$ ). (c) (d) Subcutaneous infiltrate with rimming of $\mathrm{CD}^{+}$and granzyme $\mathrm{B}^{+} \mathrm{T}$ cells around adipocytes (Immunohistochemical staining for CD8 and granzyme B, Bar $=50 \mu \mathrm{m}$ ). (e) Abdominal PET-CT: subcutaneous tissue of the abdomen wall showed thickening.

\section{DISCUSSION}

We reported here the first case of SPTCL with diffuse indurated lesions without erythema, subcutaneous tumors, or plaque, all of which are typical features of SPTCL. There have been a few two reported cases of SPTCL with unusual cutaneous manifestations including monoarthritis and chest swelling. . $^{2,3}$

Histopathologically, typical SPTCL with erythema and subcutaneous tumor displays extensive infiltration of atypical lymphocytes in the dermis and subcutaneous tissue. ${ }^{4,} 5$ In contrast, our case showed a sparse infiltrate of atypical lymphocytes without involvement of the dermis. Therefore, the histopathological differences between typical SPTCL and our case can reflect clinical ones between the two. Schramm et al. ${ }^{6}$ suggest that the lesions can be detected with PET/CT as thickened subcutaneous signal. PET/CT is useful for determining the distribution and metabolic activity of lesions in SPTCL. ${ }^{6}$ Therefore, in cases with unusual clinical manifestations, PET/CT is useful for the diagnosis of SPTCL as well 
as distribution of the disease. Dermatologists should be aware of SPTCL exhibiting diffuse subcutaneous indurations without erythema and subcutaneous tumors.

The authors declare no conflict of interest.

\section{REFERENCES}

1 Gonzalez CL, Medeiros LJ, Braziel RM, Jaffe ES. T-cell lymphoma involving subcutaneous tissue. A clinicopathologic entity commonly associated with hemophagocytic syndrome. Am J Surg Pathol. 1991;15:17-27. DOI: 10.1097/00000478199101000-00002, PMID: 1985499

2 Majeed M, Kovarik P, Puttaswamy S, Borkowsky S. Panniculitis-like T-cell lymphoma with an unusual clinical presentation. Leuk Lymphoma. 2006;47:1696-8. DOI: 10.1080/10428190600625125, PMID: 16966291
3 Sakurai E, Satoh T, Akiko YA, Maesawa C, Tsunoda K, Endo M, et al. Subcutaneous panniculitis-like T-cell lymphoma (SPTCL) with hemophagocytosis (HPS): successful treatment using high-dose chemotherapy (BFM-NHL \& ALL-90) and autologous peripheral blood stem cell transplantation. J Clin Exp Hematop. 2013;53:135-40. DOI: 10.3960/jslrt.53.135, PMID: 23995110

4 Yang SS, Su PQ, Tan KB, Aw DC. A dramatic presentation of an unusual form of cutaneous lymphoma. Indian J Dermatol. 2015;60:422. DOI: 10.4103/0019-5154.160531, PMID: 26288445

5 Miura T, Kawakami Y, Sato M, Ohtsuka M, Yamamoto T. Hemophagocytic syndrome occurred in a patient with subcutaneous panniculitis-like T-cell lymphoma without overt skin lesion: successful treatment with steroid pulse therapy. J Dermatol. 2011;38:1113-5. DOI: 10.1111/j.1346-8138.2010.01178.x, PMID: 21545491

6 Schramm N, Pfluger T, Reiser MF, Berger F. Subcutaneous panniculitis-like T-cell lymphoma with breast involvement: functional and morphological imaging findings. Br J Radiol. 2010;83:e90-4. DOI: 10.1259/bjr/69172676, PMID: 20418462 